\title{
TRAPPED IN LEGAL DISCOURSE: TRANSRACIAL ADOPTION IN THE UNITED STATES AND ENGLAND
}

\author{
Sarah Sargent*
}

\begin{abstract}
"Making the NABSW the villain of the story, making that group responsible for why black children were disproportionately in the child welfare system, misses that organization's real and substantial contribution to this debate: it tried to call attention to the ways black single mothers are targeted by the child protection systems, and tried to defend those mothers" .
\end{abstract}

There are large numbers of ethnic minority children in state child care that are awaiting adoptive families. For many, these adoptive families never materialise. This is true in the United States as well as in England. Some argue that the solution is to promote transracial adoption-for white adoptive families to adopt ethnic minority children. The idea of transracial adoption is a highly emotive one, bringing together issues of race and adoption, both of which on their own can bring forth strong visceral reactions. ${ }^{2}$

This article contrasts laws in the United States and England that govern transracial adoption of children from the state child care system. The purpose of the comparison in this article is not to identify the positive and negative aspects in each approach, nor yet to propose that one is advantageous or superior to the other. A combination of Critical Race Theory and autopoetic theory is used to show that the intention of transracial adoption laws has never, in fact, been to reduce the number of waiting ethnic minority children-despite the rhetoric that sounds in favour of transracial placements. It is not, despite claims to the contrary, a child centred practice with the ultimate aim of benefitting children. In transracial adoption, the social expectation is about preserving racial hierarchies in society, not about

\footnotetext{
* Lecturer in Law at the University of Buckingham. This article is dedicated to the memory of my godmother, Becky Vaughan, a founding member of the National Association of Black Social Workers (NABSW).

${ }^{1}$ L Briggs “Somebody’s Children” (2009) Utah Law Review 422 at 454.

${ }^{2}$ See, for instance, R-A Howe "Redefining the Transracial Adoption Controversy" (1995) 2 Duke Journal of Gender, Law and Policy 131 at 131.
} 
transcending them. ${ }^{3}$ Transracial adoption does not play a role in overcoming or changing existent social structures and hierarchies. It simply reinforces and replicates them. The use of Critical Race Theory and autopoietic theory will be used to show that transracial adoption is about satisfying the desires of prospective adoptive parents, and not about responding to the needs and interests of the large numbers of ethnic children in child care awaiting adoption.

\section{CRITICAL RACE THEORY AND AUTOPOIETIC THEORY}

Race and the place that race-consciousness should have in society, in the legal system, and in decisions regarding the adoption of children in state care, if at all, is a contentious issue. ${ }^{4}$ It is a discussion that polarises-with opposing views emotionally and passionately presented and defended. Race and adoption are issues which can bring strong visceral reactions to the fore of analysis and debate- even in legal academic discussion. The emotive content is very much part and parcel of these topics. It must be acknowledged in any analysis of transracial adoption. Because of this, any discussion on transracial adoption should identify its analytical standpoint for discussion, ontological and epistemological view from which transracial adoption is being discussed and considered. This article uses critical race theory and autopoiesis to consider the legal system and its discourse on transracial adoption.

Of course to do so breaks with the usual way in which race and law are discussed-or perhaps more importantly not discussed. This is pointedly underscored by the work of Shani King, who observes the dearth of critical consideration of the links between race and law in most family law textbooks. ${ }^{5}$ The discussion never advances beyond whether or not transracial

\footnotetext{
3 T Perry "The Transracial Adoption Controversy: An Analysis of Discourse and Subordination” (1993) 21 Review of Law and Social Change 33 at 104 comments that "choosing across racial lines [for adoption] is reserved for whites" at 104, with the expectation asserted that "white parents can parent whatever child they choose" at 107, that being ethnic minority infants. She further comments that "[t]ransracial adoption is a struggle over black babies...not the full range of Black children available.” at 86, emphasis added. See also P Quiroz "Color-blind Individualism, Intercountry Adoption Policy and Public Policy” (2007) 34 Journal of Sociology and Social Welfare 57 at 57, who states that "the real issue continues to be which children are desired by which parent.”

${ }^{4}$ Howe $n 2$ above at 131.

5 S King “The Family Law Canon in a (Post?) Racial Era” (2011) 72(3) Ohio State Journal 575.
} 
adoption serves the best interests of the child. ${ }^{6}$ But that is not the only shortcoming regarding the way in which race and family law is discussed:

"Instead of engaging in a thorough discussion of the impact of the child welfare system's impact on African-American families, family law casebooks focus on foster care in the context of adoption-such as the Indian Child Welfare Act (ICWA)—and frame racial issues around the pros and cons of interracial adoption...In short, the family law casebooks are part of the family law canon that fails to accurately and adequately describe the relationship between family law and race."7

The very important consideration of how ethnic minority children enter and remain in state care systems in disproportionate percentages does not factor into these texts. Instead transracial adoption is presented as a cure to a situation whose root causes have not been adequately explored. The fallacy of simply accepting transracial adoption as a cure without further exploration of the underlying dynamics and causes is aptly described by Ruth-Arlene Howe:

“...it was very simplistic and unethical to assume that the best way to meet the physical, social and emotional needs of Black foster children was by eliminating the practice of "same-race" placements and promoting transracial adoption (TRA). It's like building a hospital at the bottom of a cliff to treat victims of car crashes, instead of posting speed warnings and erecting a fence or other guardrail at the top to prevent cars from plunging down the cliff side., ${ }^{8}$

Despite the silence that is maintained about discussions on race and the law in the family law canon, there are other growing areas of legal scholarship that focus on not only this relationship but on the silence on it that has been maintained in much of legal discourse. Critical race theory has added a valuable perspective to discussions on race and the law. ${ }^{9}$ It is an approach to discussing, analysing and theorising about the relationship between race and law that arose from post-civil rights society to 'understand and come to grips with the more subtle, but just as deeply entrenched, varieties of racism that

\footnotetext{
${ }^{6}$ Ibid at $615-616$.

${ }^{7}$ Ibid.

${ }^{8}$ R-A Howe "Race Matters In Adoption” (2008) 42(3) Family Law Quarterly 465 at 468.

9 See generally "Introduction" in R Delgado and J Stefancic (eds) Critical Race Theory: The Cutting Edge (Temple University Press, $2^{\text {nd }}$ edn, 2000).
} 
characterize our time'. ${ }^{10}$ But Critical Race Theory brings more to analysis than a textured approach to dealing with issues of race and racial subordination. It is an approach that sees much inadequacy in the status quo and long prevailing approaches in dealing with these issues:

"Virtually all of Critical Race Theory is marked by deep discontent with liberalism, a system of civil rights litigation and activism characterized by incrementalism, faith in the legal system and hope for progress, among other things."11

Although it might be presumed that racism ceased to be a social issue after the Civil Rights movement of the 1960's Critical Race Theory proponents argue that racism remains, as much as ever, albeit in a different form. ${ }^{12}$ While it might not be as overt as it was prior to the Civil Rights movement, more covert forms remain. ${ }^{13}$ As well, Critical Race scholars contend that there has been a backlash to the Civil Rights movement which is reflected in laws which have become more punitive towards African Americans in an attempt to restore the social power balance that was upset by the Civil Rights movement. ${ }^{14}$

In its departure from liberalism, Critical Race Theory charts a much different approach for legal scholarship as well as the way in which issues of race and society are considered. Several defining tenets of Critical Race Theory are important for understanding the content of this approach. Firstly is the view that it takes towards the prevalence and persistence of racism in society:

“....racism is normal, not aberrant, in American society. Because racism is an ingrained feature of our landscape, it looks ordinary and natural to persons in the culture."15

Another important precept is the role that legal scholarship has to play. Legal scholarship is not detached and divorced from the realities it examines. Rather, there is an active part that legal scholarship can play in addressing racial inequities in society:

\footnotetext{
10 Ibid at Xvi.

${ }^{11}$ R Delgado “Critique of Liberalism” in Critical Race Theory above n 9, p 1.

12 See discussion below.

13 See discussion below.

14 See discussion below.

${ }^{15}$ Introduction n 9 above p xvi.
} 
"...we need not acquiesce in arrangements that are unfair and onesided. By writing and speaking against them, we may hope to contribute to a better, fairer world." ${ }^{16}$

Another important component of Critical Race Theory is that of 'interest convergence': ${ }^{17}$

"this concept holds that white elites will tolerate or encourage racial advances for blacks only when such advances also promote white selfinterest. Other Criticalists question whether civil rights law is designed to benefit folks of color, and even suggest that it is a homeostatic mechanism that ensures that racial progress occurs at just the right pace: Change that is too rapid would be unsettling to society at large; that which is too slow could prove destabilizing."18

Discussions of race, privilege and the social construction of these within and as part of the law may be very uncomfortable topics. The critical race perspective challenges the long-dominant positivist law and liberal doctrines that kept a silence over these very issues. In short, critical race theory provides a theoretical basis for examining questions on race and the law. Autopoiesis theory is another necessary correlate in the process of trying to understand the legal discourse on transracial adoption in the United States and England. Seen through the lens of autopoietic theory, law is a system of communication. ${ }^{19}$ As a system of communication, law interacts with and interprets the communications it receives from other systems. ${ }^{20}$ But for those communications to make sense to law, they are reinterpreted within the legal system. ${ }^{21}$

${ }^{16}$ Ibid p xvii.

${ }^{17}$ Ibid p xvii.

${ }^{18}$ Ibid p xvii.

19 M King “The “Truth”About Autopoiesis” (1993) 20(2) Journal of Law and Society 218, at 219 explains that "Autopoiesis is, then, a theoretical approach to the operations of social systems and their relationships with each other and with the general social environment.” See also M King “Children”s Rights as Communication: Reflections on Autopoietic Theory and the United Nations Convention” (1994) 57 Modern Law Review 385, 385.

${ }^{20}$ See generally C Smith “Autopoietic Law and the 'Epistemic Trap': A Case Study of Adoption and Contact” (2004) 31 Journal of Law and Society 318; M King (1994) n 20 above; M King ( 1993) n 20 above at 218; M King "Child Welfare within Law: The Emergence of a Hybrid Discourse” (1991) 18(3) Journal of Law and Society 303.

21 M King (1991) n 20 above at 308-315. 
Critical race theory scholars have offered a similar perspective as autopoietic scholars as to the role that the law plays in maintaining a social status quo in line with societal expectations. Whilst Critical Race Theory does much to uncover the concealment of racial issues within legal discourse, the use of autopoietic theory provides further analytical insight into the legal system communication on transracial adoption.

Schiff and Nobles give a concise explanation of the relationship commonalities and differences between critical legal studies (of which critical race theory is an outgrowth) ${ }^{22}$ and autopoiesis theory:

"Autopoiesis and... CLS...share a common starting point in their respective acceptance of law's indeterminacy, in the sense that the outcomes of legal decisions are not dictated, but involve choice ( they could have been other than what they were). But autopoiesis and CLS adopt a radically different approach to the conclusions to be drawn from this. For CLS law is politics, and attempts to establish any essential differences between the nature of political and legal decisions need to be unmasked and discredited. By contrast, for autopoiesis, law is not politics, just as it is not economics, or media or general social communication; politics are part of law's environment which environment it constructs for itself...,23

Critical race theory and autopoietic theory share the perspective that law as a system is a reinforcement of social status quo-and not an agent of change-which is expressed in critical race theory as 'interest convergence'. ${ }^{24}$ Autopoetic theory shares the view that the legal system does not act as a site of change, but that any change in the legal system merely is reflective of change in society and social expectations:

"For autopoiesis, the indeterminacy of all systems ( not just law), and the nature of their respective autonomies....leads to a much reduced role for the kind of choices that could be ascribed as a conscious attempt to develop law or other aspects of society in any direction.,25

\footnotetext{
22 A Harris "Foreword: The Jurisprudence of Reconstruction" (1994) 82 California Law Review 741 at 741, 743, 745-754; D Bell "Who"s Afraid of Critical Race Theory?”(1995) University of Illinois Law Review 893 at 898-901.

${ }^{23}$ R Nobles and D Schiff A Sociology of Jurisprudence (Hart Publishing 2006) Law’s Politics: Criticising Critical Legal Studies p 164.

${ }^{24}$ See discussion infra.

${ }^{25}$ Schiff and Nobles n 23 above at 164-166. Emphasis added.
} 
The legal system has a very simple way of interpreting messages and content from other systems. Autopoiesis theory explains that law interprets things in a binary manner ${ }^{26}$ — classifying them as either 'lawful ${ }^{27}$, or 'unlawful'. ${ }^{28}$ Critical race theory again informs this discussion. Harris explains that the United States still uses the system of racial classification that was the result of a 'justification for slavery. ${ }^{, 29}$ The United States had developed a bifurcated classification where a person was either white or not white. $^{30}$ This bifurcated way of understanding a person's race fits neatly into the sort of coding that autopoietic theory accords to how systems classify and understand information. It is why such binary splits are so attractive, prevalent and persistent in legal systems.

The legal system understands and operates in this simple language of bifurcated coding, and it is from this language and coding that racial relations have been managed both socially and legally inside the United States. This observation regarding autopoietic view of the legal system is an important one, particularly when addressing a legal issue as infused with visceral emotion and social expectation as that of transracial adoption. Legal systems cannot be consciously manipulated to push society in one direction or another. Legal systems responds to communications-but do not respond to a conscious choice in such a forthright matter. Law delivers what society expects. If the inequity of society is mirrored in the law, a change in the law does not change the inequities of society. ${ }^{31}$

In so doing however, 'the law masked the ideological content of race discrimination and the exercise of power required to maintain it. ${ }^{32}$ And whilst there might be claims that law no longer operates in this way, Harris responds to these claims:

\footnotetext{
26 M King (1993) n 19 above at 223.

${ }^{27}$ Ibid at 223 .

${ }^{28}$ Ibid at 223.

${ }^{29}$ C Harris, "Whiteness as Property" in ( K Crenshaw, N Gotanda, G Peller, and K Thomas eds) Critical Race Theory: The Key Writings that Formed the Movement ((1995) (The New Press New York) p 278.

${ }^{30}$ Ibid p 283-284.

${ }^{31}$ Schiff and Nobles n 23 above at 171. Schiff and Nobles n 23 above further explain that "While autopoiesis accepts that the law constitutes and reinforces inequalities of access found in the economic system, political system, media etc, these inequalities are produced separately within each system” at 171.

${ }^{32}$ Harris n 29 above at 284.
} 
"Although the substance of race definitions has changed, what persists is the expectation of white-controlled institutions in the continued right to determine meaning - the reified privilege of power...”33

This again is something that is a shared view between critical legal studies and autopoiesis theory. Schiff and Nobles explain:

"Autopoiesis and CLS both acknowledge that disparities in power affect the ability of parties to make legal communications ( namely differentiated access to law) but neither simply equates law with power ( legal right is not the same thing as wealth or the ability to coerce physically). And the claim that law, like politics, is composed of decisions that represent choices between competing values does not mean that these choices are equally open to each and every individual. ${ }^{34}$

Legal change will not result in societal change-rather societal change and changes in societal expectation result in legal system communication changes. This may be a controversial and even contestable position for proponents of white adoptive parent adoption of black children transracial adoption. This is to be expected as this message about the law removes the mask-it demonstrates the way in which legal discourse perpetuates the inequities in society—as well as the fact that there are such inequities.

\section{COLOUR-BLIND AND COLOUR-CONSCIOUS}

Race is a socially constructed category. ${ }^{35}$ Any discussion about ethnicity or race must first grapple with this idea. The prospect of comparing adoption laws in their approach to race might be seen as being made all more complex because of the differences in social construction of race. As a social construction 'referents of terms like Black and White are social groups, not genetically distinct branches of human kind. ${ }^{36}$

The idea of race is simply a reflection of social mores and customs of a given time and place, no more than that. Differing classifications of raceindeed the notion of race itself-- serves a purpose; it is 'a means of creating

${ }^{33}$ Ibid at 287.

${ }^{34}$ Schiff and Nobles n 23 above p 167.

35 See generally A Smedley and B Smedley "Race as Biology is Fiction, Race as a Social Problem is Real: Anthropological and Historical Perspectives on the Social Construction on Race” (2005) 60(1) American Psychologist 16.

${ }^{36}$ I Haney Lopez "The Social Construction of Race” in Critical Race Theory n 9 above, p 165. 
and enforcing social order, a lens through which differential opportunity and inequality are structured. ${ }^{37}$ Congruent with the way in which the legal system functions, classifications of race are created to maintain a particular status quo, and act as a mirror on social expectations on the way that the social order, privilege and hierarchy should be maintained.

A colour-blind approach is one that literally does not 'see' colour in the law. As discussed below, this is the position that has been taken in the United States federal law that deals with adoption from state child care. It is the place that English adoption policy seems to be moving. Proponents of a colour blind approach to the law present it as a desirable one that acts to provide racial equality in society:

"Advocates of the color-blind model argue that non recognition by government is clearly superior to any race-conscious process. Indeed, nonrecognition advocates apparently find the political and moral superiority of this technique so self-evident that they think little or no justification is necessary., 38

Critics of the colour-blind approach -those who call for raceconsciousness in law argue that a colour-blind approach is in fact not neutral and acts as a mask to cover over racial inequities in society:

“..the attempt to deny racial consideration, is, at its root, an attempt to hide the underlying racial oppression, a reality no amount of handwaving and obfuscation can eliminate." ${ }^{39}$

\section{TRANSRACIAL ADOPTION LAW, POLICY AND GUIDANCE IN THE UNITED STATES AND ENGLAND}

A February 2011 change in English adoption policy is heralded as ending a ban on transracial adoption placements. ${ }^{40}$ But despite the widespread perceptions, there has never been an outright legal ban on such placements being made. English adoption law, through the Adoption and Child Act 2002, requires that a child's ethnicity be taken into account when adoption

\footnotetext{
37 A Smedly and B Smedly n 35 above at 24.

38 N Gotanda "A Critique of "Our Constitution is Color-Blind” in Critical Race Theory n 9 above at 35.

39 Ibid at 37.

40 See for instance, "Ministers Tell Social Workers Not to Bar Interracial Adoption" February 19, 2011, The Guardian, http://www.guardian.co.uk/uk/2011/feb/19/ukinterracial-adoption-social-workers-guidance.
} 
placement decisions are being made. ${ }^{41}$ But transracial placements were never forbidden. It was thought that social worker reluctance to make transracial placements resulted in a growing number of ethnic minority children awaiting a match with adoptive parents - parents deemed suitable on grounds of an ethnic match - with available transracial placements bypassed to wait for an appropriate ethnic match to turn up. Thus, the policy change was announced to underscore that there was no legal ban on transracial adoptions.

The new announcement raises several questions about the perceptions that there was a ban on transracial adoption and the response to it. Given that English adoption law and policy have never banned transracial adoption, why was the choice made to address this with a policy change? What do both the perception of a ban and the choice of response say about the social expectations in English society? A policy change was not the inevitable choice to try to address the status on the law. Other apparent choices include education on the law. What then is significant about the choice of a policy statement? Is there a subtle or not so subtle shift towards a colour-blind system and away from a colour-conscious one? This seems evident given the change in statutory guidance language-discussed below. ${ }^{42}$ If there is a shift away from a colour-conscious system, what does this portend?

The United States, in response to a perceived similar situation, passed a federal law in $1996 .^{43}$ This law limited the circumstances under which an adoption placement decision could take account of the race, colour or national origin of the child or prospective adoptive parent when making adoption placements. These characteristics could be considered only in exceptional circumstances. Failure to comply with the federal law attracts heavy penalties-loss of federal funds for non-compliant agencies. ${ }^{44}$

Yet the aggressive approach to promote transracial adoption has been singularly unsuccessful in many respects. There are large numbers of AfricanAmerican children who are legally freed for adoption and yet continue to wait for an adoptive match. Statistics on children in the American child care system show that there are 107,000 children awaiting adoption. ${ }^{45}$ Of these, 29

\footnotetext{
${ }^{41}$ See discussion below.

42 See discussion below.

43 See discussion below.

44 The United States Department of Health and Human Services levied monetary penalties for MEPA-IEP violations for the first time in 2003 and a second time in 2005. Details of these actions can be found at:

http://www.hhs.gov/ocr/civilrights/activities/examples/Adoption\%20Foster\%20Care/ adoption_case_summaries.html.

45 In the complied statistics, children who do not yet have their parental rights terminated are included in this percentage as well as those children whose parent's rights to them have been terminated, leaving them legally free for adoption. It also
} 
percent of the children are classified as black - in other words, approximately 31,000 . ${ }^{46}$ The large numbers of black children who are awaiting adoption has not been substantially reduced despite the colour-blind approach mandated by American federal laws. There is a surfeit of statistical data on children in the American foster care system. A snapshot of data shows that in 2010, 12, 795 African-American children were adopted from state care systems. ${ }^{47}$ This compares to 16,554 in $2003^{48}, 13,078$ in $2007^{49}, 14,211$ in $2009 .^{50}$ According to the comprehensive review of MEPA-IEP by the Evan B Donaldson Foundation, MEPA-IEP has been a failure on a number of elements. The Evan B Donaldson report comments that 'statistics belie the expectations that transracial adoption would significantly increase adoption opportunities for older Black children. ${ }^{51}$ Moreover, as the report points out, sections of MEPA-IEP that require recruitment of black foster and adoptive families are poorly monitored-if at all-in contrast to the fierce penalties enacted if race, colour or national origin have been taken into effect when making placement decisions for a child. ${ }^{52}$

Clearly, a colour-blind approach has not solved the problem of large numbers of black children awaiting adoption. So, why is such an approach still used in the law? Why is it not being challenged as having been ineffectual in significantly reducing the number of black children awaiting adoption? And should the English legal drift towards a more colour-blind approach be of concern?

Adoption laws in the United States are generally presented as being colour-blind. This, however, is a misperception generated from the federal law that governs adoptions from federally funded adoption agencies and state

includes children who have been given a case plan goal of adoption, although the rights of their parents have not yet been terminated.

${ }^{46}$ Data from the Adoption and Foster Care Analysis and Reporting System (hereinafter "AFCARS") Administration for Families and Children, U.S. Department of Health and Human Services, shows 64,084 children had their parental rights terminated, with 107, 011 children who either had a goal of adoption or parental rights terminated. Data is from "Preliminary FY 2010 Estimates as of June 2011", at http://www.acf.hhs.gov/programs/cb/stats_research/afcars/tar/report_18.

47 "Trends in Foster Care and Adoption-FY 2002-FY 2010" at http://www.acf.hhs.gov/programs/cb/stats_research/afcars/trends_june2011.pdf (hereinafter "Trends")

${ }^{48}$ Ibid.

${ }^{49}$ Ibid.

${ }^{50}$ Ibid.

${ }^{51}$ Evan B Donaldson Foundation "Finding Families for African American Children: The Role of Race and Law in Adoption from Foster Care" (May 2008) at 34. See discussion at 33-34.

${ }^{52}$ Ibid at 35-36. 
departments. ${ }^{53}$ It is this law-and only this one-- that limits consideration of race, colour and national origin of the child or prospective adoptive placement. But this colour-blind approach has not always been present in domestic adoption laws. The United States adoption law status is somewhat confusing, given that there are multiple laws that cover adoption. There are at least four different legal scenarios for adoption. The current federal law-the Multi-Ethnic Placement Act, as amended by the Inter-ethnic Placement Act (MEPA-IEP) -- that restricts the consideration of race, colour or national origin of the child or prospective adoptive placement to very limited circumstances applies only where the child is being placed through an adoption agency or state department that receives federal funding. In most situations, these agencies are ones that provide services for children who are in the state child care system.

Secondly, adoptions of Native American children are governed by the federal Indian Child Welfare Act. Thirdly, independent adoptions-those done by agencies who do not receive federal funding-are governed by state laws. There can be a great deal of variance in state laws on specifics for adoption. Finally, intercountry adoption is governed by the Intercountry Adoption Act (IAA) and its implementing regulations, in force since April 1, $2008^{54}$

Until a change made by the Inter-Ethnic Act in 1996, United States federal law permitted taking into account the race, colour or national origin of a child or prospective foster or adoptive placement where the child was being placed through an agency that received federal funding. The original text of MEPA states:

(1) Prohibition -- An agency, or entity, that receives Federal assistance and is involved in adoption or foster care placements may not--

(A) categorically deny to any person the opportunity to become an adoptive or a foster parent, solely on the basis of the race, color, or national origin of the adoptive or foster parent, or the child, involved; or

(B) delay or deny the placement of a child for adoption or into foster care, or otherwise discriminate in making a placement decision, solely on the basis of the race, color, or national origin of the adoptive or foster parent, or the child, involved.

(2) Permissible consideration-- An agency or entity to which paragraph (1) applies may consider the cultural, ethnic, or racial background of the child and the capacity of the prospective foster or

\footnotetext{
53 The Multi-Ethnic Placement Act (1994) Public Law 103-382 as amended by the Inter-Ethnic Placement Act (1986) Public Law 104-88.

${ }^{54}$ Intercountry Adoption Act of 2000, Public Law 106-279.
} 
adoptive parents to meet the needs of a child of this background as one of a number of factors used to determine the best interests of a child.

This approach, which is very similar in text to the English Adoption and Child Act 2002 provisions, did not forbid the consideration of culture, ethnicity or race. It allowed the consideration of these factors along with other factors to determine if a placement would be in the best interests of a child. The federal law had not yet become colour-blind. But in 1996, amendments to this act changed the entire landscape of child welfare decision making. The changes made by the Inter-ethnic Placement Act limited the consideration of race, colour or national origin to exceptional circumstances. Thus, the colourblind approach to adoption became part of the American federal law.

The Inter-ethnic Act Placement provisions provide:

“...not later than January 1, 1997, provides that neither the State nor any other entity in the State that receives funds from the Federal Government and is involved in adoption or foster care placements may--

(A) deny to any person the opportunity to become an adoptive or a foster parent, on the basis of the race, color, or national origin of the person, or of the child, involved; or (B) delay or deny the placement of a child for adoption or into foster care, on the basis of the race, color, or national origin of the adoptive or foster parent, or the child, involved.. $" 56$

This seemingly benign language is not dissimilar on its face to the Adoption and Child Act 2002. However, interpretations issued by the United States Department of Health and Human Services ( HHS) made clear that any consideration of race, colour or national origin had to meet exceptional circumstances, and that the ability of parents to meet the cultural, ethnic or racial needs of the child was no longer to be part of decisions as to adoptive placements. A statement from 1998 issued by HHS underscored the impact of this new law:

"Public agencies may not routinely consider race, national origin and ethnicity in making placement decisions. Any consideration of these factors must be done on an individualized basis where special circumstances indicate that their consideration is warranted. A practice

55 Multi-Ethnic Placement Act of 1994, Public Law 103-382. Sec. 553. 42 USC 5115a. Emphasis added.

${ }^{56}$ Inter-ethnic Placement Act, Public Law 104-88. 
of assessing all children for their needs in this area would be inconsistent with an approach of individually considering these factors only when specific circumstances indicate that it is warranted. ${ }^{, 57}$

This interpretation of the statutory language restricts consideration of race, colour and national origin to circumstances where it is seen as necessary after an individual assessment of the child indicates that these need to be taken into account. Further guidance explains the constitutional basis of the interpretation as well as giving further detail on the strict limitations of when it would be considered appropriate to give consideration these factors:

"The Department's policy in this delicate area is guided by a number of complementary statutory provisions:

From the perspective of civil rights law, the strict scrutiny standard under Title VI, the Interethnic Adoption provisions and the U.S. Constitution forbid decision making on the basis of race or ethnicity except in the very limited circumstances where such consideration would be necessary to achieve a compelling governmental interest. The only compelling governmental interest related to child welfare that has been recognized by courts is protecting the "best interests" of the child who is to be placed.

Additionally, the consideration must be narrowly tailored to advance the child's interests, and must be made as an individualized determination for each child." ${ }^{58}$

The 1996 prohibitions do not apply to children who meet the definitional requirements of being an 'Indian child" ${ }^{59}$ under the 1978 Indian Child

${ }^{57}$ Answer to GAO Questions, etc.

http://www.acf.hhs.gov/programs/cb/laws_policies/policy/im/1998/im9803a.htm, Information Memorandum 98-03, Administration for Children and Families, United States Department of Health and Human Services.

${ }^{58}$ United States Department of Health and Human Services, Memorandum, June 4 1997 ,

http://www.acf.hhs.gov/programs/cb/laws_policies/policy/im/1997/im9704a1.htm

59 See section (3) of the Inter-ethnic Placement Act, Public Law 104-88. The Health and Human Services interpretation was not received without a protest from the American child welfare community. The Child Welfare League of America objected to the colour-blind interpretation of the new of law with to the then Secretary of Health and Human Services, stating that "We are in complete disagreement with the Department of Health and Human Service's interpretation of MEPA/IEP as effectively disallowing any consideration of race in adoptive and foster care 
Welfare Act (ICWA). ${ }^{60}$ The Indian Child Welfare Act was passed in $1978^{61}$ As an American federal law; it applies to all of the states within the United States. It was passed in response to the forced removal of Indian children from their homes, resulting in

“...an alarmingly high percentage of Indian families are broken up by the removal, often unwarranted, of their children from them." ${ }^{62}$

The removal was done in accordance with a philosophy that the forced assimilation of Indian children was in their best interest. ${ }^{63}$ ICWA created higher standards for the removal ${ }^{64}$ and reintegration efforts ${ }^{65}$ to be made for

placement decisions. This policy directly contradicts what we know to be best practice in child welfare." This letter is online at: http://www.cwla.org/programs/adoption/davidsletter.htm.

${ }^{60}$ The Indian Child Welfare Act was passed in 1978 (Public Law 95-608). As an American federal law, it applies to all of the states within the United States. For background and purpose on ICWA explained in recent scholarship, see generally $\mathrm{M}$ Corcoran "Rhetoric Versus Reality: The Jurisdiction of Rape, the Indian Child Welfare Act, and the Struggle for Tribal Self-Determination" (2009) 15 William and Mary Journal of Women and the Law 415, at 428-436; C Metteer Lorillard "Retelling the Stories of Indian Families: Judicial Narratives that Determine the Placement of Indian Children under the Indian Child Welfare Act” (2009) 8(2) Whittier Journal of Child and Family Advocacy 191; P Kunsesh "Borders Beyond Borders-Protecting Essential Tribal Relations Off Reservation Under the Indian Child Welfare Act" (2007) 42 New England Law Review 15.

${ }^{61}$ Indian Child Welfare Act of 1978, as amended, 2000, Public Law 95-608, 25 USC 1901 et.seq.

${ }^{62} 25$ USC 1901(4).

63 See, for instance, Child Welfare League of America apology: http://theacademy.sdsu.edu/TribalSTAR/resources/files/ApologyCWLA.pdf

"Between 1958 and 1967, CWLA cooperated with the Bureau of Indian Affairs, under a federal contract, to facilitate an experiment in which 395 Indian children were removed from their tribes and cultures for adoption by non-Indian families. This experiment began primarily in the New England states. CWLA channeled federal funds to its oldest and most established private agencies first, to arrange the adoptions, though public child welfare agencies were also involved toward the end of this period. Exactly 395 adoptions of Indian children were done and studied during this 10-year period, with the numbers peaking in 1967.... I deeply regret the fact that CWLA"s active participation gave credibility to such a hurtful, biased, and disgraceful course of action. I also acknowledge that a CWLA representative testified against ICWA at least once, although fortunately, that testimony did not achieve its end."

${ }^{64}$ See 25 USC 1912(d) and (e). 
Indian children and for the termination of parental rights ${ }^{66}$, as well as creating concurrent jurisdiction with tribal courts ${ }^{67}$, in those instances where the tribal court does not have exclusive jurisdiction. ${ }^{68}$ There are also provisions for the active involvement of the child's tribe in the state court case. ${ }^{69}$ Tribal preferences for fostering and adoption placements are to be followed ${ }^{70}$, and tribal definitions for who comprises the child's 'extended family ${ }^{, 71}$ are also to be followed in determination of fostering and adoptive placements. ${ }^{72}$

The Indian Child Welfare Act defines an Indian child as a child who is either a member of a federally registered tribe or is eligible for membership in a federally registered tribe and has a parent that is a member of that tribe. ${ }^{73}$ As the law is written, if a child meets this definition, the law is to apply to the child.

This, however, is not as straightforward as it might seem. Because of judicial resistance to the ICWA, there has been confusion and lack of clarity as to when and whether courts would apply ICWA even to those children who do meet the threshold definition of being covered by the ICWA. Judicial resistance to the act resulted in culminated with the creation of the so-called 'Existing Indian Family Exception' ${ }^{74}$ Judges used this to decide a child who,

65

Removal requires proof of active efforts made to prevent the removal of the children, in contrast to the reasonable efforts that are required by the Adoptions and Safe Families Act. Active efforts are held to be a higher standard than reasonable efforts. See 25 USC 1912

${ }^{66} 25$ USC 1912 (f). Requiring proof beyond a reasonable doubt of the need to terminate parental rights, with such proof including that of an expert witness. Most state laws require that the case for termination of parental rights be proven by a clear and convincing evidence standard for non-Indian children.

${ }^{67} 25$ USC 1911 (b). This provision requires the transfer of state court proceedings to tribal court in the absence of any good cause shown.

${ }^{68} 25$ USC 1911(a). This provides that "An Indian tribe shall have jurisdiction exclusive as to any State over any child custody proceeding involving an Indian child who resides or is domiciled within the reservation of such tribe, except where such jurisdiction is otherwise vested in the state by existing Federal law. Where an Indian child is a ward of a tribal court, the Indian tribe shall retain exclusive jurisdiction, notwithstanding the residence or domicile of the child."

${ }^{69} 25$ USC 1912(a)-regarding notice provisions to the child's tribe.

${ }^{70} 25$ USC 1915(a) and (b).

7125 USC 1915(c).

7225 USC 1903(2); 1915(a) and(b).

${ }^{73} 25$ USC 1903(4).

${ }^{74}$ This judiciary end-run on the application of ICWA was a judicial creation by the Kansas Supreme Court in the case of In re Adoption of Baby Boy L., 231 Kan. 199, 643 P.2d 168 (1982). Kansas finally abolished the doctrine in 2009 See In the Matter 
although meeting the jurisdictional definitions in ICWA of being an Indian child, was not 'Indian enough' for an application of ICWA. ${ }^{75}$ In so doing, judges then circumvented the higher standards of ICWA from being utilised in child care proceedings.

Yet, aside from drawing some attention when the Hague Convention on Intercountry adoption was first put into force in the United States in 2008, there appears to be little discomfort in the United States about the conflicting laws on how to consider issues of race. ${ }^{76} \mathrm{~A}$ child could thus be subject to any

of AJS. March 27, 2009, Supreme Court of the State of Kansas, at http://www.kscourts.org/Cases-and-Opinions/opinions/supct/2009/20090327/99130. htm. The author worked with other legal professionals in the State of Kansas to form a strategy to have this doctrine rescinded in Kansas. See comments of Professor A Organick, who created a Tribal Legal Clinic at Washburn University School of Law, Topeka, Kansas, USA, "Since I started the Tribal Court Practice Clinic (TCPC) at Washburn, I have been in a yearly cycle of reevaluating and reassessing institutional and pedagogical goals when lawyering for Indigenous people in a clinical setting. Part of the reevaluation process has to do with how Kansas deals with the Indian Child Welfare Act (ICWA) and my attempt, along with others, to reframe that debate... Last night, I spoke with a good friend and colleague from Kansas, Sarah Sargent. Ms. Sargent is an attorney and child advocate and one of the first people I met when I moved from New Mexico to Kansas. As it happens, she is also an expert on ICWA and the impact of the Existing Indian Family Exception to ICWA on Indian children and Indian tribes. She and I have worked together on a number of issues that impact children and juveniles in the state of Kansas and ICWA is always on our minds. When we spoke last night, we were trying to come up with a strategy for abolishing the Existing Indian Family Exception to ICWA in Kansas.... working on ICWA issues over the past three years has taken a lot of time.... This particular exception to ICWA isn't an issue here in New Mexico. And so, when I realized how important an issue this was, I became involved in work across the state to try and educate lawyers, social workers and judges about ICWA and about why the EIFE should be abolished in Kansas.” A Organick in "Indian Law Clinics and Externship Symposium Roundtable Discussion: Lawyering for Indigenous People” (2007) 8 Tribal Law Journal 52 at 57, 59.

75 See Baby Boy L n 74 above. See also D Lewerenz and P McCoy "The End of the "Existing Indian Family”Jurisprudence: Holyfield at 20, In the Matter of AJS and the Last Gasps of a Dying Doctrine”(2010) 36 William Mitchell Law Review 684; CL Jaffke "The "Existing Indian Family" Exception to the Indian Child Welfare Act: The States” Attempt to Slaughter Tribal Interests in Children”(2006) 66 Louisiana Law Review 733; B Atwood "The Voice of the Indian Child: Strengthening the Indian Child Welfare Act Through Children”s Participation”(2008) 50 Arizona Law Review 127; B Atwood "Flashpoints Under the Indian Child Welfare Act: Understanding State Resistance (2002) 51 Emory Law Journal 587.

${ }^{76}$ A notable exception is the research done by the Evan B Donaldson Foundation $n 51$ above. "Another exception is an article written in 1999, well before the United States law on intercountry adoption came into force-see C Metteer "A Law Unto Itself: 
one of the four laws with their differing and even conflicting approaches to considerations of race and culture, dependent upon the circumstances of their adoption. A child adopted from the United States child care system to another country is potentially subject to both MEPA-IEP and the IAA. Implementing regulations of the IAA require that 'prospective parents receive training related to transracial adoption, as well as counseling related to the child's cultural, racial, religious, ethnic, and linguistic background. ${ }^{, 77} \mathrm{~A}$ comparison with the strictures of MEPA-IEP quickly identifies the conflicting content of the two laws. It is just this sort of activity that is forbidden by MEPA-IEP. Yet this goes without much comment, let alone redress. Perhaps because the conflict is not seen as limiting adoptive parent access to children of their choosing, there is little outcry about the irreconcilable differences in the content of these two laws.

The justification for transracial adoption-that is of black children into white families - is that there are large numbers of children who would never be adopted otherwise. This much is true. The United States has a large population of children legally freed for adoption and awaiting adoptive homes. ${ }^{78}$ And in sheer numbers, the children who need to be adopted are white. ${ }^{79}$ There are no shortages of white children available for adoption. It is not only that there are not enough adoptive families for black children-there are not enough adoptive families for white children. There are not enough adoptive families for the children who are in the system.

Yet a myth is persists that there are no white children available for adoption in the United States. This simply is not true. This myth is used to justify the choice of intercountry adoption - that there are no white children in the United States that are available for adoption. The truth is that there are

The Indian Child Welfare Act as Inapplicable and Inappropriate to the Transracial/Race-Matching Adoption Controversy" (1999) 38 Brandeis Law Journal 48. For a view in opposition to that of the Evan B Donaldson Foundation report, see C Mabry “A MEPA-IEP review from Adoption Attorneys” Perspectives: Continuing to Make Permissible Assessments Based on Race for the Best Interests of Children of Color” (2009) 38 Capital University Law Review 319.

${ }^{77}$ Evan B Donaldson Report n 51 above, Executive Summary at 4.

78 Data from the Adoption and Foster Care Analysis and Reporting System (hereinafter “AFCARS”) Administration for Families and Children, U.S. Department of Health and Human Services, shows 64,084 children had their parental rights terminated, with 107, 011 children who either had a goal of adoption or parental rights terminated. Data is from "Preliminary FY 2010 Estimates as of June 2011", at http://www.acf.hhs.gov/programs/cb/stats_research/afcars/tar/report_18.

79 Ibid , showing that 39 per cent, or 42,059 children with a goal of adoption and/or whose parental rights have been terminated are white. 
white children — but not children that prospective adopters find palatable. ${ }^{80}$ They are somehow damaged goods - and rejected by prospective adopters who turn to intercountry adoption. ${ }^{81}$

\section{ENGLISH LAWS ON TRANSRACIAL ADOPTION:}

This article uses the extensive discussion regarding the American transracial adoption legal discourse as a mirror for considering the recent adoption policy changes announced in England in 2011. Of course the American and the English historical and social experiences of the issue of race are very different. Some might argue that this limits the ability to productively use one to study the other. But this article can do what the two respective legal systems cannot do themselves-draw conclusions on similarities in the legal discourse as well as differences, yet ponder on the failure of either a colour conscious or colour blind approach to deal with the issue of large numbers of ethnic minority children in care awaiting adoption from state care systems. This after all, must be the ultimate issue, the children awaiting adoption. But the question on these children is not so simple as the need to locate sufficient numbers of adoptive parents of any colour or race. The underlying question is why these children are in the child care system in such numbers in the first place.

In contrast to the United States, England has a uniform approach to its adoption laws, and does not have separate standards for adoptions that are domestic or international, or through an independent rather than government funded agency. There are no separate laws for a particular ethnic classification or heritage.

Section 1(5) of the Adoption and Children Act 2002 requires that an adoption agency give 'due consideration to the child's religious persuasion,

${ }^{80}$ A Ortiz and L Briggs “The Culture of Poverty, Crack Babies, and Welfare Cheats” (2003) 21 (3) Social Text 39. They compare the profile of children that were available for adoption from the United States care system and those that were adopted internationally into the United States from Romania, finding very little difference in the profile of the child, and questioning when then adopters made the choice to adopt from Romania: "By virtually any measure-age at adoption, aggressiveness towards peers and family, trouble getting along with other children, school problems, delinquency-these two groups of children offered the same ( considerable) behavioural and emotional challenges to their adoptive families....Finding these children so similar in so many dimensions raises a question: why did American rush to Romania...to adopt deeply troubled kids at considerable expensive to themselves and with very little formal support for raising them, when they could have adopted substantially similar children in the United States, with institutionalized support and government subsidy?” at 39.

${ }^{81}$ See generally ibid. 
racial origin and cultural and linguistic background ${ }^{82}$ Further guidance on this is given in the 2003 'Adoption: National Minimum Standards' from the Department of Health:

2.2 Children are matched with adopters who best meet their assessed needs. Wherever possible this will be with a family which:

a. reflects their ethnic origin, cultural background, religion and language; and

b. allows them to live with brothers and sisters unless this will not meet their individually assessed needs.

Where the child cannot be matched with a family which reflects their ethnic origin, cultural background, religion and language, the adoption agency makes every effort to find an alternative suitable family within a realistic timescale to ensure the child is not left waiting indefinitely in the care system. Where children cannot live with a family asset out in (a) and (b) above, a clear explanation will be given to them, having regard to their age and understanding, and be recorded. ${ }^{83}$

Ethnic matching is permitted and in fact encouraged. It is seen as preferable to transracial placement. Even so, it is not permissible to delay in adoption for a child whilst a search is made for a matching family. Children are not to be left without any family at all, lingering in care whilst the hypothetical ideal match of a same race family is pursued. However, in the face of system criticism that transracial adoptions were not being permitted, further guidance was issued. The new Guidance makes clear that it is not acceptable to delay placement with a prospective adopter on the basis that the placement would be transracial:

"If the prospective adopter can meet most of the child's needs, the social worker must not delay placing the child with the prospective adopter because they are single, older than other adopters or does not share the child's racial or cultural background." ${ }^{84}$

${ }^{82}$ S 1(5) Adoption and Children Act 2002. Emphasis added.

83 “Adoption: National Minimum Standards (2003) Department of Health, Standard 2.2, p 11. Emphasis added.

84 Adoption Statutory Guidance: The Adoption and Children Act 2002, Department for Education, p 83, paragraph 4 (updated April 19, 2011) at http://www.education.gov.uk/b0072314/guidance/ch4/match (References are made to the online version of the Guidance). 
Delay presumably would occur if the search was made for a perceived racial or cultural match whilst another adoptive home that was not a racial or cultural match for the child was available.

As well, denying a placement on the basis that it would be transracial is not permitted:

"Any practice that classifies couples/single people in a way that effectively rules out adoption because of their status, age, or because they and the child do not share the same racial or cultural background is not child centred and is not acceptable." ${ }^{85}$

The Guidance goes on to address the way in which social workers identified the ethnic heritage of a child, arguing against a simplistic black or white categorisation:

"The structure of white, black and minority ethnic groups is often complex and their heritage diverse, where the race, religion, language and culture of each community has varying degrees of importance in the daily lives of individuals. It is important that social workers avoid 'labelling' a child and ignoring some elements in their background, or placing the child's ethnicity above all else when looking for an adoptive family for the child.",86

The effort to de-emphasise ethnicity and culture as part of the adoption matching process is reflected in the new content of the 'Adoption: National Minimum Standards' issued in April 2011 by the Department for Education. ${ }^{87}$ The language of the standard 2.2 in the 2003 version is conspicuously absent from any of the adoption standards in the latest version of the adoption standards.

A colour conscious approach such as that outlined in the statute and underscored by the new Guidance arguably requires a deeper understanding of social connection and construction around issues of race than the more simplistic colour-blind approach. But research from the Adoption Research Initiative found placement decisions were made which did not show an informed view about ethnicity. ${ }^{88}$ The way in which the confusion is portrayed

${ }^{85}$ Ibid; p 83, para 5. http://www.education.gov.uk/b0072314/guidance/ch4/match. ${ }^{86}$ Ibid , p 84 para 6. http://www.education.gov.uk/b0072314/guidance/ch4/match/ethnicity-and-culture 87 Adoption: National Minimum Standards (2011) Department for Health.

88 "Summary 6: Pathways to permanence for black, Asian and mixed ethnicity children (November 2010) Adoption Research Initiatives, at 
suggests that there is a polarisation of white and non-white identities-rather than identities that are inclusive:

"Their social workers were often uncertain about whether they should be placing the child to preserve his or her present identity or to enable the development of another ethnic identity to which the child had a genetic connection." 89

There is also evidence of reluctance to place children transracially, with courts acting to over-ride social worker reluctance to place a child in a transracial or multiracial placement:

"Requests by foster carers (usually white English) to adopt minority ethnic children were often a source of professional dispute. There were often conflicting views, expressed in Courts, about whether or not it would be in the child's best interests to be moved to an ethnically matched placement. In all of such cases in the sample, the judgement went in favour of the foster carer." ${ }^{90}$

Thus, whilst the United States' MEPA law was initially very close to the English law, the legal positions on how to make placement decisions in transracial adoption diverged following the IEP amendment in 1996. Consequently, the English legal position and the American legal position on domestic adoptions from the child care system are very different. One is now colour-blind, the other colour-conscious. But there are indications of the English system drifting towards an American colour-blind approach. The most recent English statutory guidance iteration is more remarkable for what it does not say than what it does say. Whilst the English legal position on transracial adoption remains a long way from the strictly colour-blind position of the American federal MEPA-IEP law, this omission of language should not go without comment.

The English child welfare system does not have the same type of statistical data as is compiled by the United States federal government. For the first time, however, in March $2011^{91}$, a comprehensive 'datapack' ${ }^{92}$ was

www.adoptionresearchinitiative.org.uk/summaries/ARi_summary_6.pdf. See also J Selwyn, D Quinton, P Harris, D Wijedasa, S Nawaz, and M Wood Pathways to Permanence for Black, Asian and Mixed Ethnicity Children (BAAF, 2010).

${ }^{89}$ Summary 6 n 49 above at 3 .

${ }^{90}$ Ibid at 4.

${ }^{91}$ Adoption and Special Guardianship England Data Pack, Department for Education, March 2011. 
released, with some revealing information about the operation on the adoption over several years. Comments from the data pack reveal that there are black children (which the report clarifies are not ethnically mixed ${ }^{93}$ ) who wait longer for adoption than children of other ethnicities. ${ }^{94}$ It is difficult to draw statistical comparisons between the United States and England based on this disparate set of data, but one commonality is clear: there are large numbers of black children awaiting adoptive homes in both systems and that each system has concluded that transracial adoption is the way to provide a solution for the black children awaiting adoption.

\section{THE CAUSES AND CONSEQUENCES OF COLOUR- BLINDNESS}

One description of colour-blindness is that it 'becomes an alluring personal strategy to subvert racism to not see racialized differences, normalizing all persons through seeing people as people ${ }^{95}$ On the other hand, use of a colour-blind approach allows racism to exist without challenge. ${ }^{96}$ If race is not seen, racism is more difficult to challenge, as its very existence is denied in a colour-blind approach. ${ }^{97}$ If race is not seen, racism is not challenged, and the social inequities that are part of a racialised society go without challenge. A colour-blind approach to adoption placement allows a system to avoid a discussion on the deep seated racism that is part of the larger society as well as in the adoption system. ${ }^{98}$

Transracial adoption contains an element of not only rendering invisible the black mother, but the 'devaluing of Black mothers' ${ }^{99}$ — a widespread

http://www.education.gov.uk/childrenandyoungpeople/families/adoption/a0076713/da tapack

92 Ibid.

93 Ibid, stating that "The data indicate that longer placement times are especially apparent for: black children (not mixed ethnicity)”, at Slide 14.

94 Ibid, at Slide 14. There are some self-acknowledged deficiencies in the data, with the comment offered that "It is not known how many children with an adoption recommendation are never placed for adoption.” Ibid, at Slide 14.

${ }^{95}$ G Samuels "Being Raised Among White People: Navigating Racial Difference Among Adopted Multiracial Adults” (2009) 71 Journal of Marriage and Family 80, 92. Emphasis in the original.

${ }^{96}$ M Harris and W Hackett "Decisions Points in Child Welfare: An Action Research Model to Address Disproportionality” (2008) 30 Children and Youth Services Review 199, 204.

${ }^{97}$ Ibid at 204.

98 Ibid.

99 D Roberts “Unshackling Black Motherhood” (1997) 95 Michigan Law Review 938 at 938 . 
'legacy' ${ }^{100}$ in the way that the United States society has constructed Black motherhood. ${ }^{101}$

Citing the work of Dorothy Roberts, Briggs comments that:

“...invidious, if often unconscious, bias permeates the child protective system. Similarly situated children and birth parents are treated very differently...at every level of the system. Black parents are presented with impossible reunification plans, accused of things they did not do, and denied access to their children." 102

A comment from scholar R-A Howe effectively unmasks the truth, unpalatable though it might be, about the role and effects of colour-blind transracial adoption:

"From my perspective, the transracial adoption debate is about establishing a new right or entitlement for certain white adults who wish to become parents by any means they select. Proponents of transracial adoption who claim that same-race placement preferences are victimizing the increasing numbers of Black children in foster care are employing a diversionary "smokescreen" strategy. This smokescreen obfuscates important systemic problems and creates additional barriers to meeting the needs of Black children, Black families and the Black community. The focus of attention should be shifted away from the illusory debate about the merits of transracial adoption to the real issue: whether it is appropriate to establish new rights for adults seeking to adopt children.,"103

Colour-blindness not only makes racism invisible, but has the effect of erasing non-white parts of society from any recognised existence in adoption policies, according to comments in research by Perry. In her seminal article, Perry observes the damage that is done through the use of colour-blind adoption policies. In so doing she describes the social function served by colour-blind policies. She argues that a colour-blind approach simply acts to reinforce social hierarchies of race:

\footnotetext{
100 Ibid at 938 .

101 Ibid.

102 Briggs $n 1$ above at 435 .

${ }^{103}$ Howe n 2 above at 138-139.
} 
"...While rendering the Black community invisible, the discourse of colorblind individualism also reinforces the subordination of Black communities. ..."104

Some commentators see the reality of why ethnic minority children are present in such high percentages in the child welfare system as due simply ever-present racism--spoken or unspoken, acknowledged or justified-in larger society. Women and families who do not fit the image of an idealised family structure are at risk of having their children put into care for that reason alone. Wing and Weselmann comment that:

"....Mothers are presumed to be white and are discriminated against if they demonstrate that they are raced.” 105

Thus, the racial element of reasons that children of colour end up in the state child care system may in fact be the driving factor for child placementas distasteful and even controversial as this may be. ${ }^{106}$

Transracial adoption is thus a tangled web of interest and power. It is not a child centred practice that is focused about providing what is best for children. It is adult centred, with the desires and motivations of those adults that make up a privileged part of society insisting on their right to have unimpeded access to the children of their choice:

"...the transracial adoption controversy is not about addressing the needs of the many older Black children who enter the foster care system; rather it is about giving preferences to certain white adults who seek to adopt infants."

${ }^{104}$ Perry $\mathrm{n} 3$ above at 80-81.Emphasis added.

105 A Wing and L Weselmann "Transcending Traditional Notions of Mothering: The Need for Critical Race Praxis”(1999) 3 Journal of Gender, Race and Justice 257 at 268, 269, 271

106 Briggs sounds a similar note in her research, arguing that the wrong questions are being asked about child welfare and transracial adoption. She states that “...I would argue the questions we need to be asking are, why are children of color being taken from their families in such numbers and why are they so much less likely than white children to be reunited?....Similarly situated children and birth parents are treated very differently.....at every level of the system. Black parents are presented with impossible reunification plans, accused of things they did not do, and denied access to their children.” Briggs, n 1 above at 435 .

${ }^{107}$ Howe $\mathrm{n} 2$ above at 149. Emphasis in the original. 
Scholars have recently begun to explore the current relationship between race and the law. The election of Barack Obama to the US Presidency was hailed by some as evidence of a 'post-racial' ${ }^{108}$ era in the United States. ${ }^{109}$ But this is in fact not the situation at all. Rather, the legal system is just as active in maintaining the social expectations about the balance of power in American society as it was before the civil rights movement. Haney Lopez comments that current laws represent 'a backlash to civil rights' ${ }^{110}$ Shani King's research supports this, and points out that the passage of MEPA-IEP - the socalled colour-blind approach to transracial adoption-was part of this backlash against the civil rights movement. ${ }^{111}$

S King points to the importance of 'challenging...the colorblind perspective, ${ }^{112}$ of American family law. ${ }^{113}$

"Challenging the [American family law] canon will highlight its colorblind perspective and reveal the extent to which precedent allows color consciousness in family law, whether it is a situation in which not acknowledging the role of race in family law perpetuates racial inequality, or it is a situation in which not acknowledging the role of

${ }^{108}$ I Haney Lopez, "Post-Racial Racism: Racial Stratification and Mass Incarceration in the Age of Obama” (2010) 101 California Law Review 102; S King, The Family Law Canon in a (Post?) Racial Era (2011) 72(3) Ohio State Law Journal 575, 577. ${ }^{109}$ Haney Lopez n 108 above at 102-103; S King n 108 above at 577-578.

${ }^{110}$ Haney Lopez n 108 above at 109. Haney Lopez's article is focused on the large numbers of African-Americans who have been incarcerated after the Civil Rights movement. The group Human Rights Watch has also examined this situation, pointing out the "racial disparities in prison admissions for drug offences." Human Rights Watch , "Targeting Blacks: Drug Law Enforcement and Race in the United States" (2008) at 41. The report comments that "In absolute numbers, there are far more whites committing drug offences than blacks. The disproportionate rates at which blacks are sent to prison for drug offences compared to whites largely originate in racially disproportionate rates of arrest for drug offenses.” at 41. This systemic disproportionality is reflective of the American child welfare racial disparities.

${ }^{111} \mathrm{~S}$ King $\mathrm{n} 108$ above at 623. This is a view that is outlined by D Roberts $\mathrm{n} 99$ above, who comments about the revelations made by her own research: "When stories about the prosecutions of women for using drugs during pregnancy first appeared in newspapers in 1989, I immediately suspected that most of the defendants were Black women. Charging someone with a crime for giving birth to a baby seemed to fit into the legacy of devaluing Black mothers. I was so sure about this intuition that I embarked on my first major law review article based on the premise that the prosecutions perpetuated Black women's subordination. My hunch turned out to be right...” at 938.

${ }^{112}$ S King n 108 above at 640.

113 Ibid at 640 
race means not fully considering the best interests of the child. Challenging the canon will call attention to the ways in which race is still a significant factor in society, in how people arrange their private lives and families, and in the law that governs these families."

From his viewpoint, colour-blindness in the law should not go uncontested. Its presence should be acknowledged, and the way in which colour-blindness enables the continuance of racial inequities in society-and serves to mask them-must be brought to the fore. Failing to confront thisthe continuing silence of the role that colour-blind laws play in racial inequity is tantamount itself to 'promot[ing] racial inequality." 115

Research by Ortiz and Briggs also supports the assertions that the United States federal MEPA-IEP law was part of the larger backlash that occurred in the wake of the American Civil Rights movement:

"The 1997 legislation [IEP] prohibiting race matching in adoption was part of this structure masking the racial bad faith of neoconservatives and neoliberal colorblindness, a multiculturalism accompanied by the gutting of affirmative action in employment and education and the dismantling of the federal safety net for poor women and children embodied in AFDC. Perhaps more than at any time in the three decades of arguments about childhood that preceded it, the Adoption Promotion Act did not attempt to hide the contempt that was embedded in its pity of the poor.” 116

Ortiz and Briggs also argue that the fixation on poverty and the poor was simply another mask for racial bias in laws-where the term 'welfare mothers ${ }^{117}$ came to mean 'black, Latino, Native American, and less, often, Asian Women and their children'.

The 2010 Adoption Research Institute study on ethnic minority children adoption comments on the lack of information about the experiences of minority ethnic children in England:

\footnotetext{
114 Ibid.

115 Ibid.

${ }^{116}$ Ortiz and Briggs n 80 above at 51. For a view that the development of adoption in control was a form of exercising control over poor women and children, see $\mathrm{J}$ Reeves "The Deviant Mother and Child: The Development of Adoption as an Instrument of Social Control” (1993) 20 (4) Journal of Law and Society 412.

117 Ibid at 50 .

118 Ibid.
} 
"There is a shortage of data on looked after minority ethnic children, when and why they come into care, how decisions are made about their futures and what happens to them in their care careers. There have been debates about best practice in placement of minority ethnic children and this remains an area of mixed opinions."119

A similar observation was made in 1999 about the United States child care system:

“...more information is needed about the policies and practices that bring children of color into the system, as well as about the effect on all children of child welfare policies and practice. A better understanding of these issues is crucial to the discussion surrounding racial matching."120

It would seem that very little progress has been made.

\section{'TRAPPED IN LEGAL DISCOURSE'}

The messages about what is beneficial to children, about the meanings of race, culture and transracial placements all are re-interpreted by law, and become trapped in legal discourse. ${ }^{121}$ Contrary to what many would argue, transracial adoption is not at the cutting edge of social egalitarianism-far from it. Instead it is an exercise of societally bestowed privilege and poweror the lack of it:

"Changes in the letter of law which appear to favour certain social groups may also reinforce a particular image of members of that group. ...in modern pluralist societies where social realities tend to be fiercely contested, it is hardly surprising that the formal legal system, with its vested interested in maintaining its own credibility and reproductive capabilities, should be so resistant to the rapid acceptance of new versions of reality."122

119 Ibid at 1.

120 D Brooks, R Barth, A Bussiere, and G Patterson "Adoption and Race: Implementing the Multiethnic Placement Act and the Interethnic Adoption Provisions (1999) 44(2) Social Work 167 at 176-177.

121 See generally Smith n 20 above; M King (1991) n 20 above, M King (1994) n 19 above.

${ }^{122}$ M King (1993) n 19 at 232. 
Colour-blind or colour-conscious, transracial adoption law and practices only act to reinforce existing stereotypes and prejudices and racially based social hierarchy. The utilisation of transracial laws, informed by social and policy agendas, has resulted in simply maintenance of the social status quo. From the view of the autopoietic theory lens, this would come as no surprise. King argues that 'law frees us from the demand we should learn from experience. ${ }^{, 123}$ In this consideration of law, law as a system of communication cannot learn from its past experiences or from the experiences of other system. All law can do is fulfil its function which is to 'stabilize[] congruent expectations and in so doing, provide[] certainty'. ${ }^{124}$

In respect to transracial adoption then, law as a system cannot 'learn' from the experiences of other systems nor take on board historical value from past attempts to address transracial adoption. It simply manages expectations around transracial adoptive placement-and that is by -in both the United States and the United Kingdom-assuring that there is no legal barrier for white parents having ethnic minority children place with them for adoptionwhether or not this is actually occurring and whether or not white adoptive parents are seeking out these sorts of children to adopt.

King's critique of child welfare in law through an autopoietic lens provides insights into how child welfare information becomes 'trap[ped] within legal discourse'. ${ }^{125}$ Commenting upon the changes in family courts in England, he argues against any idea that child welfare and law can combine to provide solutions:

"...that those who wish to promote those developments as precursors of the family court ideal-with welfare and justice going hand-inhand as equal partners ready to solve any problems and resolve any conflict involving children's interests are deceiving themselves and those who believe in them..a genuine partnership cannot exist, for any attempt to merge child-welfare science with law as part of the legal system will inevitably result in the domination of law and the 'enslavement' of child-welfare knowledge to serve institutional objectives." 126

He further argues that attempts to merge knowledge from two different systems simply will not happen due to the autopoietic nature of systems. ${ }^{127}$ Knowledge shared across and between systems is not given the same meaning

\footnotetext{
123 M King (1991) n 20 above at 305.

124 Ibid at 305.

${ }^{125}$ Ibid at 319 .

126 Ibid at 319 .

${ }^{127}$ Ibid at 318 .
} 
as within those systems. King draws a pessimistic prediction about the ability of courts to adequately include 'parents and social services' ${ }^{128}$ as part of a partnership with the court to formulate outcomes that operate in the interests of children. ${ }^{129}$

Smith likewise draws the conclusion that law is not able to absorb social scientific thinking. Rather, she argues, in the same vein as King, that law simply reinvents the social scientific meanings fed into it in such a way that those meanings are diluted and distorted to achieve an outcome that is compatible with legal system outcomes. ${ }^{130}$ She explains in relation to postadoption contact that:

"[r]ather than integrating social scientific knowledge into its operations, law has avoided this epistemic entrapment by identifying contact arrangements and children's well-being as the (legal) responsibility of adoptive parents. It is problematic for law to import social scientific communications when its thinking is characterized by an exclusive focus on the legal consequences of adoption."

Neither King nor Smith see legal systems as being able to incorporate meaning imported from social welfare or child welfare systems in the ways that are intended to benefit children and families. That attempts to reform legal institutions seem to never meet up to expectations would not be a surprise to an autopoietic researcher.

What then are the observations that can be made through an autopoietic lens about transracial adoption? If the function of a colour-blind discourse is the continued subordination of ethnic minority communities, then the legal system will not act to alter that expectation and outcome. However positioned within child welfare, transracial adoption discourse changes its meaning when it is imported into the legal system. King points out that 'law as a discourse is not interested in consequences, but in maintaining expectations that certain consequences will occur....132 Law then is not concerned with whether transracial adoption actually increases as a result of law or policy changes, nor yet whether those placements operate for or against the interest of children. Rather, law seeks to not fall short of meeting expectations, and where the expectation of transracial adoption in legal discourse is to maintain racially hierarchical social strata, law is not troubled in the least. The tools for seeking change in the child welfare system lose their potency when transferred to legal

\footnotetext{
128 Ibid at 319

${ }^{129}$ Ibid at $319-320$.

${ }^{130}$ Ibid at 309.

131 Smith n 21 above at 337.

${ }^{132}$ M King (1991) n 21 above at 309.
} 
systems - and account for the lack of progress in resolving racial disparity of ethnic minority children in child welfare systems. The tools for change simply have become trapped within legal discourse. Until or unless that can be recognised and unravelled, it will make no difference to the outcomes whether the law takes a colour-blind or colour-conscious approach.

\section{CONCLUSION}

This article has compared the differing approaches to transracial adoption in the United States and England. It has focused on the laws that govern adoption from state child care systems. The US has multiple laws that govern adoption and the content of these conflicts as to whether and how to consider issues of race, culture and ethnicity when making adoption decisions for children. The law that governs adoption from the state child care system moved from a colour-conscious to a colour-blind system, where it is forbidden to give consideration to race, colour or national origin except in very limited and exception circumstances. The impetus for this change was the belief that transracial placements of ethnic minority children to white adoptive parents were not being made. In the same vein, England has announced a change to its adoption policies, underscoring that its laws do not ban transracial placements. Whilst it is required to give consideration to issues of culture and ethnicity in English law, transracial adoptions have not in fact been banned in the law. Instead, social workers interpreted the law in ways that made it seem as if transracial placements were not being made-based in part upon social worker's own individual interpretations of laws, of ethnic heritage and what they felt was best for a child. The furore over transracial adoption in both countries has been characterised as an issue over whether white adoptive parents were being denied the child of their choosing-with some commentators suggesting that the children of interest are infants, not older ethnic minority children. This being the case, transracial adoption is simply an exercise of and reflection of existent racially based social hierarchies. Far from transforming inequities in society, when reinterpreted by legal systems, transracial adoption policies simply maintain a status quo. Autopoietic theory argues that nothing more can or should be expected from child welfare meanings being introduced into legal systems. Rather, law simply absorbs these and re-interprets them in ways congruent with the legal system and its function of maintaining expectations-causing the meanings to become 'trap[ped].. within the legal discourse. ${ }^{133}$

Thus, to beg the question then of 'how' to affect change and free children from the trap of legal discourse, a few final thoughts and comments are

133 Ibid at 319. 
offered. Shani King comments on the entrenched social views that Americans have on the structure of their society and the role that colour-blind views have played in forming and maintaining that view:

"Partly through colorblindness and partly through the accumulate weight of cultural beliefs and historical practices, most Americans accept that major American institutions are race-neutral and that these institutions produce vast racial disparities. If this is so, then simply informing whites about dramatic race-correlated differences will not challenge, let alon[e] change their beliefs, because they already recognize and accept such inequalities as a legitimate feature of social reality. Indeed, with racial injustice seemingly a natural condition, an emphasis on numbers alone will tend to solidify rather than destabilize dominant understandings of society's basic fairness."134

It is clear that a colour-blind approach is a part of the problem, and certainly no part of the solution in addressing the social situations that have resulted in the large numbers of ethnic minority children awaiting -futilely in most cases - adoption. Haney Lopez calls for an outright rejection of colourblindness and of undertaking a process instead which can begin to invite the sort of social changes that is needed to combat the situation that has resulted in the over-representation of ethnic minority children in the state child care system. ${ }^{135}$ He calls for the development of a 'countervailing narrative about race as a form of social stratification. ${ }^{136}$

But, accepting the autopoietic view that legal systems mirror social expectations and that they themselves are not sites of change, a counternarrative is not going to be enough to affect the sort of change that Haney Lopez calls for. It is a place to start-but that narrative is not going to displace the well-entrenched social stratification that permeates American society. The narrative must eventually change social mores and messages and expectations. Then and only then will the legal system respond in such a way that it does not result in racial hierarchy. What direction the English legal system goes through its role in maintaining and reflecting social expectation-whether it continues a drift towards colour-blindness or retains its colour-conscious qualities with all that each positions entails-- remains to be seen.

\footnotetext{
134 Haney Lopez n 108 above at 142.

135 Ibid at 143 .

136 Ibid.
} 